\title{
LICENCIATURA EM EDUCAÇÃO DO CAMPO: O TEMPO COMUNIDADE COMO POTENCIALIZADOR DE UMA FORMAÇÃO DOCENTE CRÍTICA E TRANSFORMADORA
}

\author{
Licensing in Field Education: community time as the potentializer of critical and transforming teaching
}

José Antonio Ferreira Leandro ${ }^{1}$

Keylla Rejane Almeida Melo ${ }^{2}$

Catarina de Bortoli Munhae ${ }^{3}$

\begin{abstract}
RESUMO: A Pedagogia da Alternância tem demonstrado sua viabilidade no atendimento às populações campesinas. A integração entre diferentes tempos e espaços formativos traz uma nova perspectiva para as universidades, no sentido de articular efetivamente ensino, pesquisa e extensão e favorecer a relação indissociável entre teoria e prática. O objetivo deste trabalho é apresentar resultados do projeto de intervenção "Horta pedagógica como instrumento de ensinoaprendizagem para uma educação contextualizada", realizado de 2016 a 2018, na Escola Zenita Pires Ferreira, localizada na comunidade São Joaquim, zona rural de Campo Maior (PI). Participaram do projeto, educandos do $5^{\circ}, 6^{\circ}$ e $9^{\circ}$ anos do Ensino Fundamental, além de professores, secretário da escola, como também, algumas famílias da comunidade. Apesar dos inúmeros desafios, o trabalho foi produtivo para a escola, pois a utilização da horta apresentou-se como uma ferramenta instrumental e norteadora para os educadores na forma de ensinar os conteúdos curriculares, tornando suas aulas mais agradáveis e significativas. A horta pedagógica possibilitou aos estudantes trabalharem em grupo e observarem como a natureza age, vivenciando na prática conhecimentos teóricos. A execução do projeto demonstrou que este trabalho atraiu a participação engajada de alunos e professores, além de ter promovido interação entre eles.
\end{abstract}

Palavras-chave: Horta pedagógica. Educação contextualizada. Formação de professores.

ABSTRACT: Pedagogy of Alternation has demonstrated its viability in serving rural populations. The integration between different times and formative spaces brings a new perspective for universities, in the sense of effectively articulating teaching, research and extension and favoring the inseparable relationship between theory and practice. The objective of this work is to present the results of the intervention project "Pedagogical garden as a teaching-learning tool for contextualized education", carried out from 2016 to 2018, at Escola Zenita Pires Ferreira, located in the São Joaquim community, in the rural area of Campo Maior ( PI). Participating in the project were students from the 5th, 6th and 9th years of elementary school, in addition to teachers, school secretary, as well as some families in the community. Despite the countless challenges, the work was productive for the school, as the use of the vegetable garden was presented as an instrumental and guiding tool for educators in the way of teaching curricular content, making their classes more pleasant and meaningful. The pedagogical garden allowed students to work in groups and observe

${ }^{1}$ Licenciado em Educação do Campo/Ciências da Natureza pela Universidade Federal do Piauí (UFPI). E-mail: joseferreira-10@,hotmail.com

2 Doutora em Educação pela Universidade Federal de Uberlândia (UFU). Professora do Curso de Licenciatura em Educação do Campo (LEdoC) da Universidade Federal do Piauí (UFPI), Campus Ministro Petrônio Portella (CMPP), em Teresina (PI). E-mail: keyllamelo@ufpi.edu.br

${ }^{3}$ Doutora em Ciências Biológicas (Zoologia) pela Universidade Estadual Paulista Júlio de Mesquita Filho (UNESP). Professora do Curso de Licenciatura em Educação do Campo (LEdoC) da Universidade Federal do Piauí (UFPI), Campus Ministro Petrônio Portella (CMPP), em Teresina (PI). E-mail: catarina@gmail.com 
how nature acts, experiencing practical theoretical knowledge. The execution of the project demonstrated that this work attracted the engaged participation of students and teachers, in addition to promoting interaction between them.

Keywords: Pedagogical garden. Contextualized education. Teacher training.

\section{CONSIDERAÇÕES INICIAIS}

A formação inicial docente através da metodologia da Pedagogia da Alternância ${ }^{4}$ é uma proposta ainda em construção, porém, diversos estudos (MOLINA, 2017; CALDART, 2011) têm demonstrado sua viabilidade no atendimento às populações campesinas. A integração entre diferentes tempos e espaços formativos (Tempo Universidade e Tempo Comunidade $^{6}$ ) traz uma nova perspectiva para as universidades, no sentido de articular efetivamente ensino, pesquisa e extensão e favorecer a relação indissociável entre teoria e prática. A atuação na comunidade como parte intrínseca da carga horária de formação propicia ao licenciando ir além da aprendizagem do ser professor, repensando as formas de organização da escola e da comunidade e mobilizando os diferentes agentes para um processo de transformação em benefício dos sujeitos do campo.

Este estudo apresenta resultados do projeto de intervenção "Horta pedagógica como instrumento de ensino-aprendizagem para uma educação contextualizada”, desenvolvido de 2016 a 2018 na Escola Zenita Pires Ferreira, localizada na Comunidade São Joaquim, zona rural do município de Campo Maior (PI). A principal motivação para efetivação deste trabalho foram os estudos sobre educação do/no e para o campo realizados no Curso de Licenciatura em Educação do Campo (LEdoC)/Ciências da Natureza da Universidade Federal do Piauí, Campus Ministro Petrônio Portella, Teresina (PI). O projeto, cujo objetivo foi promover atividades sustentáveis e integradoras do currículo escolar utilizando a horta como instrumento pedagógico para uma

\footnotetext{
${ }^{4}$ A Pedagogia da Alternância surgiu em 1935, na França, protagonizada por camponeses, insatisfeitos com a educação tradicional, distante das demandas educacionais do meio rural, e desejosos por implantar um modelo de educação que dialogasse com as especificidades do campo. Portanto, uma escola que oferecesse uma formação profissional voltada à produção agrícola, permitindo o desenvolvimento do meio rural (FRAZÃO; DÁLIA, 2010). Essa proposta metodológica articula diferentes tempos e espaços formativos, de modo alternado: Tempo Escola e Tempo Comunidade. No Brasil, a Pedagogia da Alternância foi instalada em 1968, por meio do Movimento de Educação Promocional do Espírito Santo (MEPES), que fundou as três primeiras escolas famílias agrícolas brasileiras. A adoção da Pedagogia da Alternância pelos Cursos de Licenciatura em Educação do Campo visa fortalecer os vínculos identitários dos estudantes com o campo, além de facilitar o acesso e a permanência no Curso.
}

${ }^{5}$ Tempo Universidade (TU) - período em que os estudantes ficam na Universidade realizando atividades acadêmicas do Curso, relacionadas ao estudo teórico dos componentes curriculares.

${ }^{6}$ Tempo Comunidade (TC) - período em que os acadêmicos desenvolvem atividades de pesquisa e intervenção no espaço socioprofissional em que residem e/ou trabalham. 
aprendizagem contextualizada, nasceu como proposta do Tempo Comunidade (TC) do referido Curso, mas foi sendo ampliado transformando-se em ação contínua no âmbito da escola.

A opção pela horta pedagógica como instrumento de ensino e aprendizagem para contextualização dos conteúdos visou fortalecer na escola a discussão e a compreensão da agricultura familiar como traço fundamental da cultura camponesa, bem como, o desenvolvimento de técnicas de cultivo para o trabalho em equipe, o respeito e a responsabilidade pelos alimentos cultivados e pela natureza. Acredita-se que envolver educandos e educadores em práticas agrícolas agroecológicas pode fortalecer a identidade dos alunos como sujeitos do campo, problematizando questões como sucessão rural, desenvolvimento sustentável e soberania alimentar.

É de grande valia, tanto para a escola e, especialmente para os estudantes, trabalhar com projetos dessa natureza, pois os mesmos podem relacionar os conteúdos escolares com saberes do seu cotidiano, despertando o interesse e o gosto por aprender, já que tais conteúdos são tratados de forma mais significativa para eles. A partir do trabalho com a horta, os professores das disciplinas de Ciências, Geografia e Matemática buscaram contextualizar alguns dos conteúdos escolares, além de explorarem valores humanos, respeito à natureza, solidariedade, esperando que cada educando desenvolvesse tais conteúdos e posturas em suas respectivas comunidades. A relação entre escola-família-comunidade também foi fortalecida com a implementação do projeto.

Construir uma horta no ambiente escolar não é somente para economizar. É ter um espaço de formação humana que extrapola as quatro paredes da sala de aula, possibilitando uma educação socioambiental, crítica, cidadã e, principalmente, política, no sentido de que os sujeitos possam criar, no coletivo, condições para a organização intencional e sistemática da escola e de suas práticas pedagógicas. É poder ter acesso a um laboratório vivo e rico nas diversas áreas do conhecimento e facilidade para preparar as refeições dos alunos com diferentes tipos de hortaliças, enriquecendo cada vez mais a alimentação. É aprender a cultivar plantas, alegria, saúde, troca de saberes; é ter um espaço cheio de cores e sabores.

\section{A EXECUÇÃO DO PROJETO: CAMINHOS PERCORRIDOS}

O desenvolvimento do projeto de intervenção "Horta pedagógica como instrumento de ensino-aprendizagem para uma educação contextualizada" possibilitou a afirmação da Pedagogia da Alternância como princípio metodológico que contribui para uma formação docente crítica e emancipada. Os estudos desenvolvidos no Tempo Universidade (TU) oportunizam uma atuação comunitária consistente, planejada intencionalmente, no sentido de transformar estruturas tradicionais enraizadas tanto na escola como na comunidade. 
A execução de um projeto de intervenção, concebido de forma participativa entre licenciando e membros da comunidade escolar, configura-se como uma estratégia eficaz no sentido de materialização dos princípios da Educação do Campo, pois possibilita uma análise coletiva do contexto, partindo de uma intenção de mudança ou inovação, constituindo-se, então, em práticas a serem (re)avaliadas continuamente e ressignificadas, a partir dos dados criados no processo de implementação das atividades.

O projeto de intervenção foi fundamentado nos pressupostos da pesquisa-ação, definida, genericamente, por Tripp (2005, p. 443) como "toda tentativa continuada, sistemática e empiricamente fundamentada de aprimorar a prática".

Foi exatamente esta tentativa que se propôs realizar. Porém, algumas dificuldades apresentaram-se no decorrer da implementação do projeto, como pouca disposição e habilidade de alguns professores em articular os conteúdos com as práticas na horta; falta de recursos materiais; tímida adesão das famílias; pouco apoio do órgão municipal de educação, dentre outras. Foi, portanto, desafiador para a escola e buscou-se contornar tais dificuldades, com o apoio do propositor do projeto, estudante da LEdoC/Ciências da Natureza no planejamento das práticas, articulando conteúdos escolares às práticas na horta, no fornecimento de mudas e sementes; com o estabelecimento de parcerias com o Sindicato dos Trabalhadores Rurais de Campo Maior (PI) para doação de materiais para a construção e a irrigação dos canteiros e também, o apoio de algumas famílias para a construção e manejo da horta, junto aos alunos e funcionários da escola.

Pode-se afirmar que, mesmo diante dos desafios, o trabalho foi produtivo para a escola, pois a utilização da horta apresentou-se como uma ferramenta instrumental e norteadora para os educadores na forma de ensinar os conteúdos curriculares, de modo a tornar as aulas mais agradáveis e significativas aos educandos.

\subsection{Campo de intervenção}

O projeto foi desenvolvido na Escola Zenita Pires Ferreira, fundada em nove de junho de 1952. A mesma contava com um total de 101 alunos em 2016 na fase inicial do projeto e, em 2018, com 136 alunos, divididos da pré-escola ao $9^{\circ}$ ano do Ensino Fundamental. Localizada na comunidade São Joaquim, zona rural do município de Campo Maior (PI), $39 \mathrm{~km}$ da sede do município.

A escola, durante o processo de implementação do projeto, ganhou um novo prédio, mais amplo, arejado, que conta com seis salas de aulas, uma cantina, espaço administrativo, pátio coberto, laboratório, auditório, biblioteca e sala de Atendimento Escolar Especializado (AEE). Nos 
anos em que durou a execução do projeto, o quadro de funcionário da escola contava com um corpo docente composto por 16 professores, incluindo a diretora e a coordenadora pedagógica, um secretário escolar, dois vigilantes e uma merendeira.

Para implantação da horta, foi utilizado um terreno de $4 \mathrm{X} 4 \mathrm{~m}$, totalizando $16 \mathrm{~m}^{2}$, localizado na escola, que tem grande área ociosa. O local foi adequado para se trabalhar, pois ofertava todas as condições para um bom desenvolvimento das plantas, próximo à fonte d'água e com incidência de luz solar na maior parte do dia.

\subsection{Sujeitos}

Como sujeitos do projeto foram selecionados inicialmente, no ano de 2016, os educandos da turma do $9^{\circ}$ ano do Ensino Fundamental, que ao todo eram 15 estudantes, sendo nove do sexo masculino e seis do sexo feminino, na faixa etária entre 14 e 15 anos. Nos anos de 2017 e 2018, os alunos do $5^{\circ}$ e $6^{\circ}$ ano foram envolvidos no projeto: 11 alunos do $5^{\circ}$ ano e 12 alunos do $6^{\circ}$ ano, com idades entre 10 e 12 anos. Todos são jovens residentes em comunidades campesinas, sendo que algumas ficam próximas à comunidade São Joaquim, e outras distantes, em média, até $30 \mathrm{~km}$. Estes alunos são transportados em ônibus coletivos, disponibilizados pela Secretaria Municipal de Educação de Campo Maior.

Também participaram do projeto, de forma mais frequente, três professores das disciplinas de Matemática, Geografia e Ciências, bem como, o secretário da escola, que manifestaram em suas falas e práticas as expectativas e os desafios na construção de uma organização didático-pedagógica mais contextualizada. Nas turmas de $5^{\circ}$ e $6^{\circ}$ anos, a disciplina de Ciências foi a única contemplada.

Esses sujeitos tiveram papel ativo durante todo o processo, desde o preparo do solo até o período de colheita dos frutos, mas sempre relacionando as práticas com os conteúdos estudados durante as aulas.

\subsection{Etapas de execução do projeto}

Inicialmente, aplicou-se um questionário com o objetivo de diagnosticar o consumo de hortaliças pelos alunos, obtendo-se os seguintes dados: cerca de 99\% consumiam hortaliças diariamente, mas poucos as cultivavam, em média, 15\%. Em seguida, organizou-se uma roda de conversa com a equipe gestora, secretário escolar, professores das disciplinas de Ciências, Geografia, Matemática e alunos do $9^{\circ}$ ano para socialização dos resultados do diagnóstico e 
elaboração do esboço do projeto de intervenção, que foi sistematizado por José Antonio Leandro, estudante da LEdoC, na época, e Técnico em Agropecuária.

A apresentação do projeto para a comunidade escolar aconteceu em março de 2016, na própria escola, contando com a presença de alguns pais de alunos, membros da comunidade, representantes da Prefeitura Municipal de Campo Maior (PI), representantes do Sindicato dos Trabalhadores Rurais de Campo Maior, representantes da Secretaria Municipal de Desenvolvimento Rural (SMDR), representantes da Defesa Civil, equipe de funcionários da escola e professoras da Universidade Federal do Piauí (UFPI), orientadoras do estudante da LEdoC/Ciências da Natureza, propositor do projeto. Na oportunidade de apresentação do projeto, foi realizada palestra sobre a importância da horta escolar na Educação do Campo.

Com o intuito de fortalecer a proposta de intervenção, mostrando para alunos e professores a viabilidade da educação contextualizada, foi realizado intercâmbio para a Escola Família Agrícola Santa Ângela (EFASA), em Pedro II (PI), com as turmas do $8^{\circ}$ e $9^{\circ}$ anos, professores das disciplinas de Ciências, Português e Matemática, a diretora, a coordenadora, as merendeiras e o idealizador do projeto de intervenção.

Aulas teóricas e práticas foram sempre conciliadas para que os alunos pudessem ter base teórica para as aplicações práticas. Estas aplicações foram:

$\checkmark$ Realização de compostagem para o cultivo das hortaliças;

$\checkmark$ Capina do mato e revolvimento da terra;

$\checkmark$ Demarcação dos 03 canteiros (1 m X 5 m, cada um);

Nivelamento dos canteiros;

$\checkmark$ Plantio na sementeira;

$\checkmark$ Transplantio para a horta;

$\checkmark$ Manejo contínuo da horta.

Foi realizado ainda, um processo de sensibilização de toda a comunidade escolar, quanto à higiene necessária para a manipulação de alimentos e quanto à importância da horta pedagógica, feito pelos próprios alunos envolvidos no projeto, através de palestras.

\section{PESQUiSA E AÇÃO: PROCESSOS QUE SE ENTRECRUZAM NO TEMPO COMUNIDADE ATRAVÉS DA INTERVENÇÃO}

De forma contínua, sistemática e empiricamente fundamentada (TRIPP, 2005), buscouse aprimorar a prática dos professores de modo que a educação contextualizada seja uma realidade na Escola Zenita Pires Ferreira. A horta pedagógica configurou-se como um dispositivo importante 
para o alcance de tal finalidade, à medida que permitiu articular teoria e prática, conhecimentos escolares e saberes do cotidiano, além de trazer para a escola um aspecto fundamental da cultura camponesa: a agricultura familiar.

A educação contextualizada é baseada na realidade dos sujeitos campesinos, valorizando suas experiências, especificidades, cultura e seus valores. Cabe à escola, reconhecer e valorizar aspectos dessa realidade, articulando-os à ação pedagógica, de modo a desenvolver atividades que tenham relação direta com o cotidiano de seus alunos e de suas famílias sem, no entanto, desconsiderar os conteúdos escolares, mas, ao contrário, relacionando-os às vivências dos educandos. Nesse sentido, a educação contextualizada fortalece a identidade camponesa. Menezes; Araújo (2007, p. 40) afirmam:

Ao falar em contextualização, estamos falando em "identificação da ruptura", ou seja, estamos rompendo com as grandes narrativas da ciência e da pedagogia moderna que são os princípios da formalidade abstrata e de universalidade, da concepção tradicional e colonizadora da educação, ao mesmo tempo reafirmando que a educação precisa fazer sentido na realidade das pessoas no lugar onde estão.

A partir da execução do projeto de intervenção, percebeu-se que materializar uma educação contextualizada ainda é desafiador para educadores no âmbito escolar, em virtude de estes terem sido formados numa perspectiva tradicional, colonizadora, isto é, o professor como o único detentor de conhecimentos e os alunos como sujeitos passivos no processo de ensino e aprendizagem, a partir do qual se ensinam conteúdos desfragmentados, apartados da realidade. Dessa forma, transformar suas práticas no sentido de oferecer um ensino baseado no contexto dos sujeitos campesinos, apreciando suas vivências, saberes, cultura e valores é um aprendizado a longo prazo, que requer o rompimento com um modelo tradicional, que ainda prevalece nas escolas do campo.

Segundo Menezes; Araújo (2007, p. 40), na concepção da educação contextualizada, “a construção dos saberes se dá na relação das pessoas com o mundo, consigo mesmas e com os outros". Há, portanto, um diálogo permanente entre a realidade sociocultural dos educandos e a escola, sendo tal realidade, ponto de partida e de chegada para o trabalho com os conteúdos escolares, pois os saberes do cotidiano são ressignificados a partir dos conhecimentos científicos aprendidos.

Nesse sentido, observou-se que criar uma horta na escola é uma boa estratégia pedagógica, pois os estudantes têm a oportunidade de trabalhar em grupo e, observarem como a natureza age, vivenciarem na prática, os conhecimentos teóricos. A execução do projeto demonstrou que essa 
possibilidade atrai a participação engajada de alunos e professores, além de promover uma interação entre eles.

A horta como ferramenta pedagógica enriquece o currículo no sentido de se trabalhar de forma contextualizada os conteúdos escolares, pois a mesma, além de proporcionar estudos, pesquisas e descobertas, oferece estratégias de mudanças nos hábitos alimentares e o debate acerca de questões ambientais e nutricionais. Possuir uma horta escolar possibilita ainda, exercitar o trabalho pedagógico dinâmico, prazeroso, participativo e interdisciplinar. Segundo Cribb (2010, p. 50):

[...] a horta escolar é o espaço propício para que as crianças aprendam os benefícios de formas de cultivo mais saudáveis. Além disso, aprendem a se alimentar melhor, pois como se sabe, as crianças geralmente não gostam de comer verduras e legumes e o fato de cultivar o alimento que levarão para casa os estimula a comê-los, especialmente quando conhecem a origem dos vegetais e sabem que são cultivados sem a adição de insumos químicos.

Obteve-se ótimos resultados durante o processo de implementação do projeto de intervenção, tais como: recebimento de uma minibiblioteca da Embrapa; envolvimento dos professores e alunos nas atividades da horta; intercâmbio com a Escola Família Agrícola Santa Ângela (EFASA), de Pedro II (PI). Com a minibiblioteca, os alunos puderam desenvolver conhecimentos específicos sobre as mais diversas hortaliças e aprofundar os conhecimentos sobre Agroecologia, que corresponde ao campo de conhecimentos que proporciona as bases científicas para apoiar o processo de transição do modelo de agricultura convencional para estilos de agricultura familiar de base ecológica ou sustentável. Nesse sentido, contribuiu como fonte de pesquisa para os mais diversos tipos de culturas que foram cultivadas, possibilitando aos alunos construírem conhecimentos a serem aplicados em suas comunidades.

No intercâmbio, foi ministrada oficina de cultivo de hortaliças pelo monitor da escola, que abordou desde a produção do composto orgânico à confecção das mudas. O coordenador pedagógico da EFASA proferiu palestra sobre a Pedagogia da Alternância e as contribuições do cultivo da horta, tanto para contextualizar os conteúdos, quanto para a vida do jovem na comunidade. Foi uma importante oportunidade para educadores e educandos conhecerem novas experiências, trocarem saberes e assim, fortalecerem os trabalhos no âmbito do projeto de intervenção.

O intercâmbio serviu tanto para os professores buscarem formas de articular os conhecimentos escolares com as práticas na horta, como para docentes e discentes compreenderem as etapas fundamentais para o cultivo das hortaliças. Nas disciplinas de Ciências e Matemática, por exemplo, nas primeiras aulas a partir do início da execução das atividades do projeto, foi possível 
explicar de forma bem sucinta e de fácil entendimento aos educandos, como acontece a relação entre carbono-nitrogênio, processo de decomposição, seres decompositores, volume, $\mathrm{m}^{2}$, perímetro.

No tocante à atividade de produção do composto orgânico, coordenada pela professora da disciplina de Ciências e pelo idealizador do projeto, para os alunos do $9^{\circ}$ ano, estes puderam compreender que o esterco é um dos materiais necessários para o processo de produção do adubo utilizado na horta. Ele é formado por excrementos sólidos e líquidos dos animais e pode estar misturado com restos vegetais. Sua composição é muito variada. São bons fornecedores de nutrientes, tendo o fósforo e o potássio rapidamente disponíveis e o nitrogênio fica na dependência da facilidade de degradação dos compostos (ARAÚJO et al., 2010).

Os vegetais representam um material benéfico à vida do solo por vários aspectos: por ajudar na cobertura do solo, alimentar microrganismos, liberar nutrientes, como nitrogênio, potássio, cálcio, carbono e fósforo. Plantar ajuda, portanto, a sustentar a vida no planeta. Uma atividade é sustentável quando tem a capacidade de se manter através do tempo (MOURA et al., 2017). De acordo com o posicionamento das autoras, podemos afirmar que as atividades relacionadas com a horta pedagógica são sustentáveis, pois possibilitam uma tomada de consciência dos sujeitos sobre sua responsabilidade pessoal e coletiva com a vida na Terra, como, por exemplo, a forma correta como se deve produzir e consumir os alimentos. A partir de estudos empíricos realizados com a produção de horta escolar, Pereira; Melo; Melo (2017, p. 120) afirmam:

\footnotetext{
Ao serem criadas situações, como no caso uma horta, em que as crianças possam lidar com a terra, regando todos os dias e acompanhando o crescimento das plantas, caminha-se em uma trilha educacional que extrapola as paredes da sala de aula. Além disso, a prática do professor aproxima-se de uma perspectiva de educação mais ampliada e integradora, que tenta superar uma visão reducionista e fragmentada do processo de ensino-aprendizagem.
}

Os aspectos citados pelas autoras são elementos-chave no processo de educação contextualizada. Focando-se no potencial da horta pedagógica, diariamente, os alunos cuidam da horta, regando, acompanhando o crescimento e o desenvolvimento das plantas, além de compreenderem cientificamente alguns processos de produção, como a compostagem, que pode ser estudada de forma contextualizada na disciplina de Ciências.

Ao longo do processo de desenvolvimento das atividades, verificou-se que trabalhar as aulas com práticas educativas voltadas para a produção de alimentos no espaço da horta é uma forma de tornar o ensino e aprendizagem mais harmonioso e participativo, mas não é uma prática fácil de ser desenvolvida, porque é desafiadora para educadores, que precisam ter domínio do 
conteúdo, já que em tais aulas surgem diversas indagações, dúvidas e perguntas sobre o que está sendo trabalhado.

Ao contextualizar-se os conteúdos nas atividades na horta, é importante refletir com os educandos sobre a interação, o cuidado e o respeito com a natureza e a cultura, destacando a diversidade da relação homem, natureza, sociedade. "Convém desenvolver nos anos finais do ensino fundamental o raciocínio crítico, prospectivo e interpretativo das questões socioambientais bem como a cidadania ambiental" (MOURA et al., 2017, p. 49).

Nessa perspectiva, destacamos a aula prática realizada com a turma do $5^{\circ}$ ano do Ensino Fundamental, de plantio de mudas de hortaliças, em junho de 2017, sob orientação dos técnicos em agropecuária José Antonio (idealizador do projeto) e Marcos Portela, ambos prestadores de serviços da Secretaria Municipal de Desenvolvimento Rural (SMDR) de Campo Maior (PI). Os técnicos levaram uma diversidade de espécies de mudas, tais como: tomate, pimentinha, macaxeira, pimentão e feijão guandu. Inicialmente, explicaram como seria a metodologia da aula e, em seguida, falaram sobre os tipos de hortaliças, o solo mais apropriado para o cultivo, número de espécies de cada tipo, período de colheita e a importância de se cultivar as mesmas, de modo que a explicação partiu da realidade e dos conhecimentos prévios dos sujeitos que estavam envolvidos no momento.

A horta pedagógica viabilizou o processo de interdisciplinaridade e a contextualização de alguns dos conteúdos abordados em sala de aula. A seguir, apresentamos alguns conteúdos que foram tratados de forma mais significativa a partir deste trabalho.

- Matemática - Conteúdos: área, volume, as quatros operações.

- Geografia - Conteúdos: clima, tipo de solo, fome e tipos de plantações.

- Ciências - Conteúdos: ciclo de produção, ciclo da água, nutrição alimentar, processo de compostagem, tipo de solo, semente, sistema radicular das plantas, relações e interações das plantas, pragas e doenças relacionadas com as hortaliças, importância do uso e manejo do solo para produção de alimentos, carboidratos, lipídios, proteínas, gorduras, vitaminas, minerais, tipo de folha, caule, flores, frutos, armazenamento de alimentos e o processo de higienização destes.

- Língua Portuguesa - Redação sobre vários temas e intepretação de textos.

Diante do exposto, é possível afirmar que as práticas educativas relacionadas com a horta pedagógica mostraram-se dinâmicas e proveitosas durante todo o processo de ensino e aprendizagem, pois utilizar a horta como ferramenta pedagógica é ter um leque de possibilidades de tornar as aulas mais agradáveis, prazerosas e significativas a todos os sujeitos envolvidos com o processo de educação contextualizada. 


\section{CONSIDERAÇÕES FINAIS}

A análise da experiência de intervenção empreendida na escola Zenita Pires Ferreira possibilita compreender como o TC proposto pelo Curso de Licenciatura em Educação do Campo/Ciências da Natureza ofertado pela Universidade Federal do Piauí (UFPI), Campus Ministro Petrônio Portella, em Teresina (PI), não apenas fortalece os vínculos comunitários, como também, viabiliza processos de transformação no contexto da escola e da comunidade.

O estudante da LEdoC/Ciências da Natureza, em seu processo formativo para a docência, atuou a partir do conhecimento de sua realidade já que numa etapa anterior ao Curso, teve a oportunidade de inventariar esta realidade e escolher, participativamente com a comunidade, um aspecto a ser transformado. Assim, no caso da experiência analisada, o estudante idealizador do projeto decidiu por uma atuação centrada no contexto da escola onde estudou durante os anos finais do Ensino Fundamental. A sua formação técnica em agropecuária e os estudos realizados durante o TU, tanto na área de Ciências Sociais e Humanas, quanto na área de Ciências da Natureza, contribuíram para alicerçar o trabalho que apresenta, ainda, uma perspectiva desafiadora para a escola, haja visto o caráter tradicional e colonizador das práticas educativas nas instituições escolares.

Porém, é possível afirmar que o objetivo definido para o projeto de intervenção, qual seja, promover atividades sustentáveis e integradoras do currículo escolar utilizando a horta como instrumento pedagógico para uma aprendizagem contextualizada foi alcançado, não sem dificuldades, mas com persistência e estudos, conseguiu-se transpor os desafios. Sabemos que o caminho a ser trilhado é longo, mas gratificante pela possibilidade de êxito.

O trabalho com a horta pedagógica como ferramenta de ensino e aprendizagem para uma educação contextualizada provocou momentos de reflexão docente, ampliando, de forma significativa, as práticas de ensinar/aprender dos sujeitos envolvidos nas atividades. Temos o propósito de que os professores cheguem a uma consciência da sua ação cotidiana, utilizando novos métodos de trabalho com os conteúdos de suas disciplinas, tornando mais harmoniosa a relação professor/aluno e, claro, melhorando os índices de aprendizagem na escola.

Desse modo, concluímos que a intervenção empreendida ofereceu importantes contribuições à ação educativa da escola, no sentido da incorporação da educação contextualizada como organização curricular e princípio metodológico. No entanto, a concretização desse objetivo mais amplo depende, antes de tudo, de dedicação e de formação continuada de todo o corpo docente, alunos, demais funcionários, famílias, além do estabelecimento de parcerias com órgãos competentes do município e outros sujeitos e instituições. 


\section{REFERÊNCIAS}

ARAÚJO, Wildjaime Bergmam Medeiros de et al. Esterco caprino na composição de substratos para formação de mudas de mamoeiro. Ciênc. agrotec., Lavras, v. 34, n. 1, p. 68-73, jan./ fev., 2010.

CALDART, R. S. Caminhos para transformação da escola: reflexões desde práticas da Licenciatura em Educação do Campo. São Paulo: Expressão Popular, 2011.

CRIBB, Sandra Lucia de Souza Pinto. Contribuições da Educação Ambiental e Horta Escolar na promoção de melhorias ao Ensino, à Saúde e ao Ambiente. Revista Eletrônica do Mestrado Profissional em Ensino de Ciências da Saúde e do Ambiente, Rio de Janeiro, vol. 3, n. 1, p. 42-60, 2010.

FRAZÃO, Gabriel Almeida; DÁLIA, Jaqueline de Moraes Thurler. Políticas Públicas e organização social no Ensino Agrícola: reflexões sobre a construção e o desenvolvimento dos CEFFAS Fluminenses. In: VIII Congreso Latinoamericano de Sociología Rural, Anais... Porto de Galinhas, 2010.

MENEZES, Ana Célia Silva; ARAUJO, Lucineide Martins. Currículo, contextualização e complexidade: espaço de interlocução de diferentes saberes. Caderno Multidisciplinar, v. 04, p. 33-49, 2007. Disponível em: < http://www.irpaa.org/publicacoes/artigos/artigo-lucin-anacelia.pdf. >. Acesso em: 16 out. 2017.

MOLINA, Mônica Castagna. Contribuições das Licenciaturas em Educação do Campo para as políticas de formação de educadores. Educ. Soc., Campinas, v. 38, nº 140, p. 587-609, jul.-set., 2017.

MOURA, Anaisa Alves et al. Educação Ambiental. Aiamis [Recurso digital]. 2017. Disponível em: <

http://md.intaead.com.br/geral/pedagogia/educacao ambiental/mobile/index.html\#p=3. $>$. Acesso em: 13 dez. 2017.

PEREIRA, L. A.; MELO, K. R. A.; MELO, R. A. Atuação comunitária na LEdoC: produção de horta escolar com utilização de materiais recicláveis. In: MELO, K. R. A.; MELO, R. A.;

CATAPRETA, J. C. A. (Orgs.). Saberes e fazeres da Educação do Campo: reflexões sobre a formação de professores e a prática educativa. Teresina: EDUFPI, 2017. p. 105-124.

TRIPP, David. Pesquisa-ação: uma introdução metodológica. Trad. Lólio Lourenço de Oliveira. Educação e Pesquisa, São Paulo, v. 31, n. 3, p. 443-466, set./dez., 2005. 